Rapid Reviews COVID-19

\title{
Review 2: "The Personal Responsibility Pandemic: Centering Solidarity in Public Health and Employment Law"
}

\author{
Michael C. Duff ${ }^{1}$
}

${ }^{1}$ Professor of Law, University of Wyoming College of Law

Published on: Sep 14, 2020

DOI: $10.1162 / 2$ e3983f5.9328aef6

License: Creative Commons Attribution 4.0 International License (CC-BY 4.0). 


\section{$\underline{\text { RR:C19 Evidence Scale rating by reviewer: }}$}

- Strong. The main study claims are very well-justified by the data and analytic methods used. There is little room for doubt that the study produced has very similar results and conclusions as compared with the hypothetical ideal study. The study's main claims should be considered conclusive and actionable without reservation.

\section{$* * * * * * * * * * * * * * * * * * * * * * * * * * * * * * * * * * * * * * *$}

\section{Review:}

Law professors Lindsay Wiley and Samuel Bagenstos make the case, in their article The Personal Responsibility Pandemic: Centering Solidarity in Public Health and Employment Law, that the United States response to the coronavirus pandemic has failed because both the American public health system and American employment law are insufficiently "soladiristic." At the root of such solidarity, they note, is human interconnectedness. The authors further contend that in the public health context "within a matter of weeks it became clear that the virus thrived on socio-economic injustice, ableism, and structural racism." The authors emphasize what they characterize as "overwhelming evidence that African Americans, Native Americans, Latinos, Latinas, and people with low socioeconomic status were contracting the virus and dying from it at sharply disproportionate rates." This disproportionate disease contraction resulted from these groups' higher exposures to the virus in both workrelated and residential settings. It has also been apparent that the virus has enhanced impact on populations already possessing higher rates of chronic cardiovascular and lung diseases. As the authors emphasize, these types of already existing conditions function as "social determinants of health" predisposing certain groups to severe illness and death from COVID-19.

If public health is described as "what we as a society do collectively to assure the conditions in which people can be healthy," a national plan based on appeals to individuals to act "responsibly" is not a public health policy at all. We can implore individuals to engage in physical or social distancing, for example; but without also providing citizens with adequate paid leave from work, unemployment compensation, personal protective equipment, or something as basic as the ability to wash their hands at work, we are engaging in mere sloganeering and not assuring the conditions in which people can be healthy. 
The authors push back against strands of scholarship that have argued against expansive views of public health steeped in notions of fundamental societal transformation. Against claims that transformative public health is a threat to individual freedoms, for example, the authors persuasively argue that sweeping individualistic narratives have been revealed during the coronavirus pandemic as stark oversimplifications. Freedom and liberty, after all, depend fundamentally upon health. As the authors put it, "solidarity can be liberty-promoting in the face of a public health crisis with potential for enormous social, economic, and cultural disruption."

The structure of the article is in two parts: one focused upon public health law; the other upon employment and antidiscrimination law. At first blush the two parts may not appear harmonious, but as the authors explain: "effective pandemic prevention and response demands a public health response rooted in solidarity, which in turn requires employment and antidiscrimination reforms to enable everyone to follow public health guidance for the protection of themselves and others." To put matters simply, there are times when workers should not work because their employment exposes them to high risk of contracting COVID-19. If, despite the existence of such risks, society compels "essential" workers (comprised heavily of low wage workers and workers of color) to remain at work, concepts of solidarity demand fair treatment of those workers. Dangerous, virus-promoting workplaces should be cleaned and otherwise made as safe as feasible. If workers accidentally contract COVID-19 at work, they should be adequately compensated for the harm they have sustained.

Yet, as the authors explain, the Occupational Health and Safety Administration (OSHA) has been criticized for not creating enforceable pandemic-specific safety standards, and workers have not been reliably provided with workers' compensation benefits. The authors correctly note that a primary obstacle to achieving these objectives is a fault/responsibility paradigm that essentially informed employment law rules. This is perhaps not surprising. Workers' compensation, for example, the oldest of American employment laws, was originally conceived as a Grand Bargain-an exchange of statutory benefits for common law liability. Furthermore, OSHA imposes penaltiesliability-for non-compliance with safety standards. In short, the concept of liability boils down to a defendant's invasion of a plaintiff's legally protected interest. The entire work injury scheme is grounded in individualistic, status-based rights violations (claims may not even be brought unless a plaintiff has "standing" to sue; that is, unless individual concrete rights have been violated) — which is, broadly speaking, one of the major distinctions between workers' compensation/OSHA enforcement and federal structures of true social insurance (Social Security and Medicare, for example). 
As if to underscore the authors' decision to treat public health and employment law and antidiscrimination law in unison, the early-August breakdown in Congressional stimulus negotiations seems to have been driven in substantial part by individual fault/immunity considerations: "no liability immunity, no deal." Public health considerations have not as yet breached this impasse.

In the end, one might view this very helpful article as a sustained argument for a comprehensive reimagining of a soladiristic American social insurance infrastructure. Such a universal structure may be necessary to rectify evident unjust distribution of public health burdens and benefits; and to transform current laws that "center personal responsibility and blame in ways that contribute to and exacerbate economic injustice and structural racism, rather than preventing or ameliorating harm." 